\title{
EFFECT OF VARIOUS PROTECTIVE SOLUTIONS ON FUNCTION AFTER KIDNEY TRANSPLANTATION
}

\author{
Monika Hrabalováa ${ }^{a *}$, Petr Bachledaa , Lucie Lubuškáa, \\ Zdeněk Kojeckýa, Josef Zadražil ${ }^{b}$ Karel Krejčíb, Sadek Al Jabry ${ }^{b}$ \\ a $\quad I^{\text {st }}$ Clinic of Surgery, Faculty of Medicine, Palacky University, Olomouc, Czech Republic \\ $3^{\text {rd }}$ Clinic of Internal Medicine, Faculty of Medicine, Palacky University, Olomouc, Czech Republic
}

Received: November 5, 2004; Accepted (with revisions): December 17, 2003

Key words: Organ preservation / Protective solutions / Hypothermy / Cellulous ischaemia / Organ removal / Reperfussion /Transplantation

From 1995 to 2002 we monitored a group of 127 patients who had undergone kidney transplantations in the Olomouc transplantation centre. The aim of our study was to assess the function of the kidneys after the transplantation, which were rinsed during the removal from cadaverous donors and afterwards were treated by different preservative dilutions. We divided the patients into three groups of approximate similar size, according to the used dilution - EC (Eurocollins), HTK (Custodiol) and UW (Viaspan). In the first three weeks we assessed in each group, the immediate function of the kidneys as primary, belated and afunction. The EC group showed the primary function in $51.2 \%$ of cases, belated in $46.8 \%$ of cases and afunction in $2.1 \%$ of cases. In the HTK group, primary function was found in $73.7 \%$, belated $23.6 \%$ and afunction $2.7 \%$. The results of the UW group came to primary function $71.5 \%$, belated $26.2 \%$ and afunction $2.3 \%$. The criteria of the immediate but also the long-term function (five year investigation) was a serum creatinine figure. The lowest decline of creatinine in three weeks after the transplantation was noticed in the EC group (the average figure $=429 \mu \mathrm{mol} / \mathrm{l}$ ). In contrast the HTK group (the average figure $279 \mu \mathrm{mol} / \mathrm{l}$ ) and the UW group (the average figure $288 \mu \mathrm{mol} / \mathrm{l}$ ) had comparable figures and there was no significant difference between them from the statistical point of view. It means later in the first, the third and the fifth year after the transplantation the figures levelled out: EC $154 \mu \mathrm{m} / 1$, HTK $182 \mu \mathrm{m} / 1$, and UW $133 \mu \mathrm{m} / 1$. There was statistically a minimum significant difference between the HTK group and the UW group. Another criteria was to determine the amount of functional grafts in alive donees. The Assessment was carried out always in each year after the transplantation, altogether five years. The amount of the functional renal grafts in EC and HTK group was $100 \%$, in the UW group $76.9 \%$.

Conclusion: HTK and UW gave better immediate functionality results, but there were no differences found among EC, HTK and the UW group from the long-term point of view.

\section{INTRODUCTION}

The preservation of organs is a process, whose objective is to ensure the functional viability of organs to be transplanted. The organs are taken from living donors and we are talking about both blood related and unrelated transplants or brain death cadaverous donors. Organ removal and transplantation are governed by Transplantation Law ${ }^{1}$.

The objective of organ preservation is to ensure, that the removed organs can be rinsed and, using balanced solutions, various organs can be in fact, preserved with their morphological and biochemical features. During induced hypothermy, different protective solutions have a different protective effect. Energy reserves for maintaining structural protection are limited during the anaerobiosis period. All anaerobic protective procedures concentrate on protection of all organ functions (functional protection), on protection of energy reserves (energy protection) and protection of morphological structures (structural protection) $)^{2}$.
The principle of preservation during ischaemia includes steps against unavoidable acidosis (intra- and extra cellular) and prevention of critical $\mathrm{pH}$ level, steps to maintain cell volume, especially endothelial cells, steps for optimal utilization of anaerobic energy reserves and finally maintaining cell structure, which is necessary for future preservation of the transplanted organ. In the decision making process with regard to the use of various protective procedures, the criterion of instantaneous restitution of organ function appears to be more important than the criterion of sustaining cell viability during an ischaemic period.

The preservation of organs begins the moment they are rinsed in the donor's body. Ischaemic changes occur soon after circulation stops. At present, practically all the organs designated for transplantation are treated with protective solution inside the donor's body (so called in situ process). Removal of organs and subsequent treatment with protective solutions is considered obsolete.

The extent of ischaemic damage in different organs is variable and irreversible changes within a few minutes can 
be seen in brain cells, while skin cells survive for many hours without a supply of oxygen. The kidney tolerates ischeamia longer than brain tissue, bud not as long, however, as skin cells.

Induced hypothermy, used in organ preservation aims to lower an organs metabolic requirements, maintain viability of the macro- and microvascularization interstice, parenchyma and outlets utilizing physiological and pharmacological means and strategically integrate removal, preservation and subsequent implantation into suitable recipient so, that organ function following transplantation is instantaneous ${ }^{3,4}$.

At Olomouc Transplant Center for organ preservation and other institutions, Eurocollins (EC), Custodiol (HTK) and Viaspan (UW), were used for removal before EC became obsolete in the second half of the nineties. At present, most of Czech transplant centers and the Eurotransplant center use Custodiol.

\section{Eurocollins}

The basic principle of the EC solution is that owing to its electrolytic composition, it simulates the intracellular environment. It contains phosphate buffer and as a carrier of osmotic activity for maintaining $420 \mathrm{~m}$ Osmol level, glocose is used. This has the disadvantage that lactate produced from fissured glucose at low temperatures and hence greater hypothermy is a substrate inducing an acidosis and cell oedema. Many studies show that this effect can be prevented by substituting glucose for another saccharide, for example saccharose ${ }^{6}$.

\section{Mechanism of the effect}

High concentration of potassium and low concentration of sodium and chlorides are similar to their intracellular concentration, glucose permeates only very slowly through the cellular membrane, stimulates cellular anaerobic glycolysis and thisincreases tissue acidosis.

\section{Custodiol}

Experimental work on kidney protection began in 1978. In 1985, solution with histidine content began to be used in heart transplans. Later studies showed equally good protective effects in liver and lung transplantation $^{8}$.

\section{Mechanism of the effect}

Its composition, which approaches the value of cytoplasmic levels, and simultaneous lowering of calcium concentration to values of cytoplasm in dormancy cell stabilize the cell membrane potential to a level which is close to normal dormancy potential and this prevents intracellular entry of $\mathrm{Na}$ and calcium, which activate cellular activity. Manitol, contained in the solution, is metabolically inert. It is not subjected to transport mechanisms and acts as an anti-oxidant. It also eliminates cellular oedema. Tryptophan has a membrane protection effect, potassium-hydrogen 2-ketoglutarate is a substrate for aerobic generation energy. Histidin and histidinhydrochloride act as a buffer. This buffer capacity causes a significant slowdown of the typical decrease in $\mathrm{pH}$ in tissues related to organic ischaemia. The slowdown of the $\mathrm{pH}$ decrease improves and increases the effect of anaerobic glycolytic energy production under isachaemic conditions from $50-60 \%$ to $90 \%$ of energy turnover. Custodial is also used for protection of heart, liver, pancreas, lung and vein transplants.

\section{Viaspan $^{9,10}$}

In English speaking countries, UW is considered the "golden standard" for liver, kidney and pancreas preservation. Osmotic concentration is maintained metabolically through inert substrates as, for example, lactobionate or raphinoss. Hydroethyl-starch, which minimizes interstitial oedema, is used as a colloid carrier. Glutathione, allopurinol and adenosine, which function as neutralisers of free oxygen radicals, are also added.

\section{Mechanism of the effect}

Potassiumlactobionate is substituted by chloride ions and in combination with raphinosis acts highly effectively in preventing cellular swelling.

\section{WORK OBJECTIVE}

This study compares the effects of various protective solutions on transplanted kidney function in all patients who underwent transplantation at the Transplantation Center of Olomouc University Hospital from 1995-1997. With these patients, the input parameters for waiting list and for the actual selection for transplantation are comparable.

The major objective was to evaluate function of the transplanted kidney at two time periods:

1. immediately after the kidney transplant and during the first year of its functioning.

2. over the long- term (five year time period), and to determine, whether the protective solution has any effect on the long term functioning of the transplanted kidney.

\section{RESULTS}

The patients population: 127 patients in total were selected for the study. Of these e 85 were males $(65.3 \%)$ and 42 females $(34.7 \%$ ), The age range was 23-72 (Table 1).

In each group, we evaluated primary function, delayed function, afunction of transplanted kidney. (Table 2-4, Graph 2-4) and creatinine and glomerular filtration levels (Table 5-6, Graph 5-6).

Creatinine values and number of functional grafts in living recipients after kidney transplant in percentages (Table 7) were considered to be the basic evaluation of long term function of transplanted kidney in relation to the protective solution and these values were processed statistically. Number of functional grafts in living reci- 
pients and their percentage expression were also processed statistically. The glomerular filtration values were not, at present, considered sufficiently valid in outside patients and therefore were not statistically processed.

Table 1. Number of patients selected for study in three fiveyear time periods ${ }^{\mathrm{a}}$.

\begin{tabular}{|c|c|c|c|c|}
\hline \multirow{3}{*}{ Solution } & \multicolumn{3}{|c|}{ Time period monitored } & \multirow{2}{*}{ Total } \\
\cline { 2 - 4 } & $\begin{array}{c}1995 \\
-2000\end{array}$ & $\begin{array}{c}1996 \\
-2001\end{array}$ & $\begin{array}{c}1997 \\
-2002\end{array}$ & \\
\hline EC & 20 & 13 & 14 & 47 \\
\hline HTK & 16 & 11 & 11 & 38 \\
\hline UW & 10 & 13 & 19 & 42 \\
\hline
\end{tabular}

a See graph 1

1. Immediate results - up to three weeks after transplant.

Table 2. EC protective solution ${ }^{\mathrm{b}}$.

\begin{tabular}{|l|c|c|}
\hline Graft function & Number & Percentage \\
\hline $\begin{array}{l}\text { Primary } \\
\text { function }\end{array}$ & 24 & 51.1 \\
\hline $\begin{array}{l}\text { Delayed } \\
\text { function }\end{array}$ & 22 & 46.8 \\
\hline Afunction & 1 & 2.1 \\
\hline Total & 47 & 100.0 \\
\hline
\end{tabular}

\begin{tabular}{|l|l|l|}
\hline $\begin{array}{l}\text { Death within } \\
5 \text { years after Tx }\end{array}$ & 12 & 25.5 \\
\hline
\end{tabular}

${ }^{\mathrm{b}}$ See graph 2.

Table 3. HTK protective solution ${ }^{\mathrm{c}}$.

\begin{tabular}{|l|c|c|}
\hline \multicolumn{1}{|c|}{ Graft function } & Number & Percentage \\
\hline $\begin{array}{l}\text { Primary } \\
\text { function }\end{array}$ & 28 & 73.7 \\
\hline $\begin{array}{l}\text { Delayed } \\
\text { function }\end{array}$ & 9 & 23.6 \\
\hline Afunction & 1 & 2.7 \\
\hline Total & 38 & 100.0 \\
\hline
\end{tabular}

\begin{tabular}{|l|l|l|}
\hline $\begin{array}{l}\text { Death within 5 } \\
\text { years after Tx }\end{array}$ & 10 & 26.3 \\
\hline
\end{tabular}

Table 4. UW protective solution ${ }^{\mathrm{d}}$.

\begin{tabular}{|l|c|c|}
\hline Graft function & Number & Percentage \\
\hline $\begin{array}{l}\text { Primary } \\
\text { function }\end{array}$ & 30 & 71.5 \\
\hline $\begin{array}{l}\text { Delayed } \\
\text { function }\end{array}$ & 11 & 26.2 \\
\hline Afunction & 1 & 2.3 \\
\hline Total & 42 & 100.0 \\
\hline
\end{tabular}

\begin{tabular}{|l|l|l|}
\hline $\begin{array}{l}\text { Death within } \\
5 \text { years after Tx }\end{array}$ & 6 & 14.2 \\
\hline
\end{tabular}

d See graph 4.

2. Long-term results.

Table 5. Development of average values of serum creatinine in $\mu \mathrm{mol} / \mathrm{l}^{\mathrm{e}}$.

\begin{tabular}{|c|c|c|c|c|}
\hline \multirow{2}{*}{ Solution } & \multicolumn{4}{|c|}{ Time period monitored } \\
\cline { 2 - 5 } & 3rd week & $1^{\text {st }}$ year & $3^{\text {rd }}$ year & $5^{\text {th }}$ year \\
\hline EC & 429 & 154 & 173 & 154 \\
\hline HTK & 279 & 154 & 181 & 182 \\
\hline UW & 288 & 128 & 128 & 133 \\
\hline
\end{tabular}

${ }^{\mathrm{e}}$ See graph 5.

Table 6. Development of average values of glomerural filtration in $\mathrm{ml} / \mathrm{s} 1.75 \mathrm{~m}^{2 \mathrm{f}}$.

\begin{tabular}{|c|c|c|c|c|}
\hline \multirow{2}{*}{ Solution } & \multicolumn{4}{|c|}{ Time period monitored } \\
\cline { 2 - 5 } & 3rd week & 1st year & 3rd year & 5th year \\
\hline EC & 1.15 & 1.13 & 0.9 & 0.93 \\
\hline HTK & 1.15 & 1.15 & 0.79 & 0.87 \\
\hline UW & 1.26 & 1.21 & 1.03 & 1.02 \\
\hline
\end{tabular}

${ }^{\mathrm{f}}$ See graph 6.

Table 7. Number of functional grafts in living recipients after kidney transplant in percentage.

\begin{tabular}{|c|c|c|c|}
\hline \multirow{2}{*}{ Years } & \multicolumn{3}{|c|}{ Type of solution used } \\
\cline { 2 - 4 } & EC & HTK & UW \\
\hline 1. & 100 & 100 & 92.3 \\
\hline 2. & 94.1 & 100 & 92.3 \\
\hline 3. & 100 & 100 & 84.6 \\
\hline 4. & 92.8 & 100 & 76.9 \\
\hline 5. & 100 & 100 & 76.9 \\
\hline
\end{tabular}

c See graph 3. 

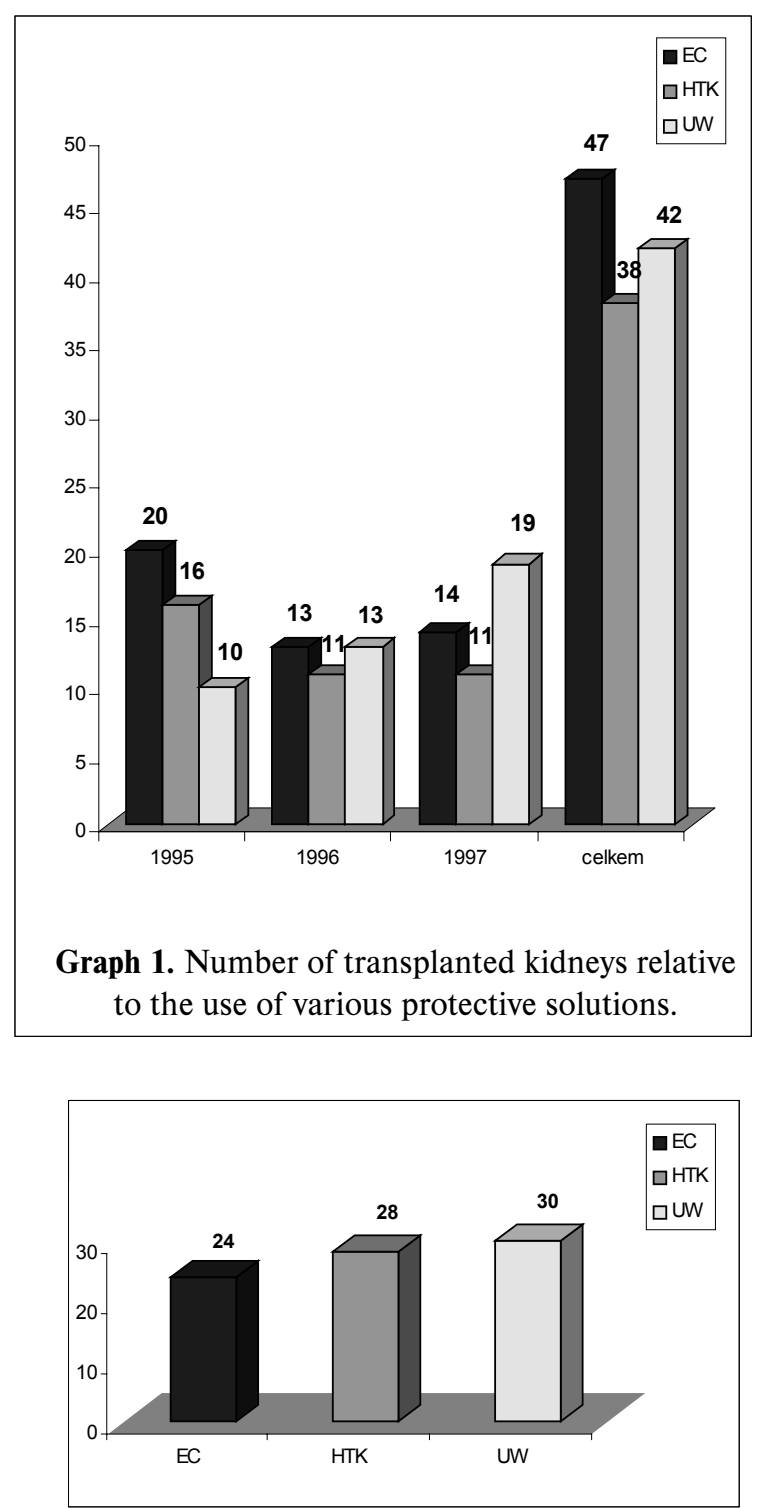

Graph 2. Primary function.

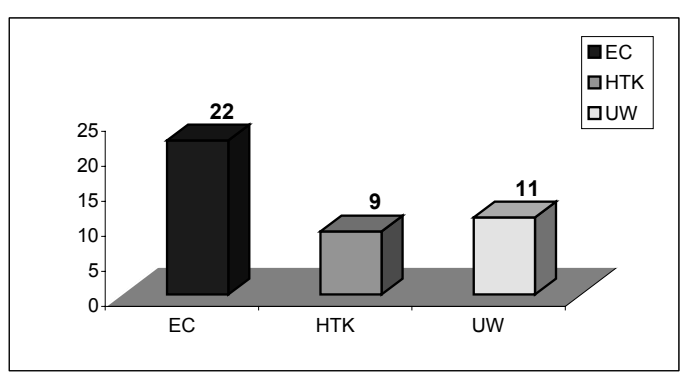

Graph 3. Delayed function.

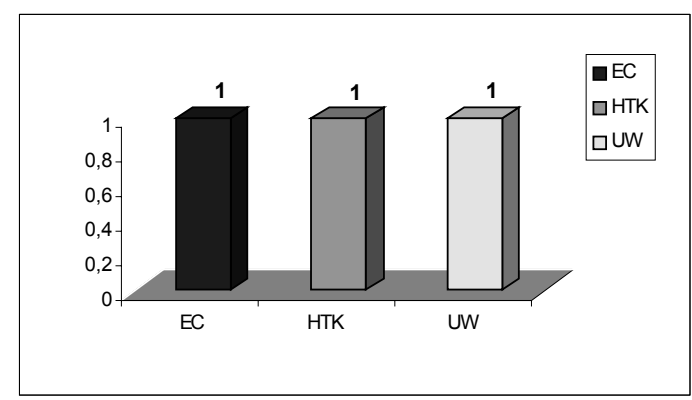

Graph 4. Afunction.

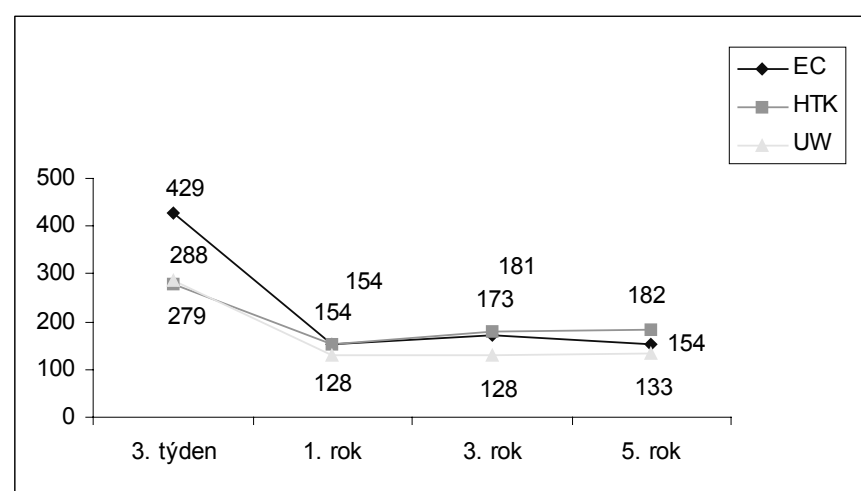

Graph 5. Monitoring of average serum creatinine levels.

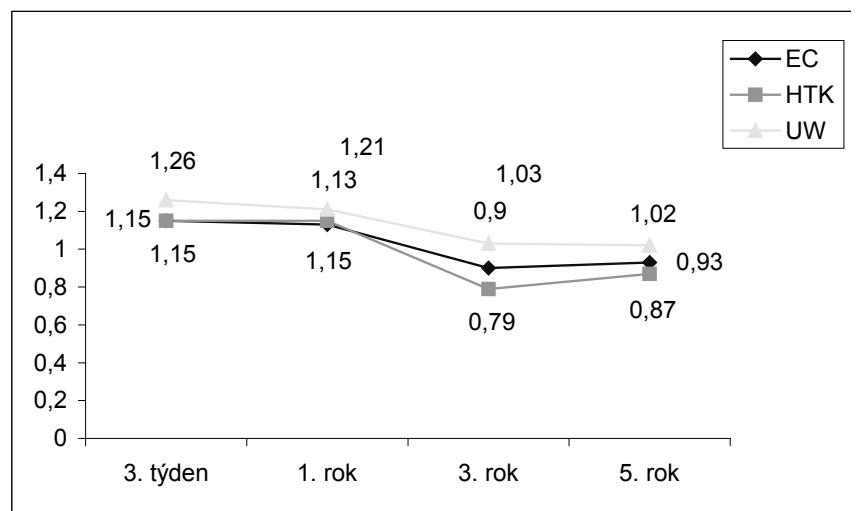

Graph 6. Monitoring of glomerular filtration values. 


\section{DISCUSSION}

To date, problems with organ preservation problems are known in detail. All the mechanisms at the cellular and sub-cellular levels have been clarified, the biochemical processes, ion movements intra- and extracellular, effects of metabolic products as well as enzyme action, which take place during ischaemia, hypothermy and subsequent reperfission have been researched.

Detailed knowledge of these mechanisms, supported especially by an improved technical background, have resulted in producing various methodologies and the various rinsing and protective solutions, which are presently used.

The study we began from the time evaluate the effects of various protective solutions on the function of grafts when use of Eurocollins (EC) solution was a matter of routine as no other solution was available; practical use of more "sophisticated" solutions, specifically Viaspan (UW) and Custodiol (HTK), were considerably more expensive, and were only slowly emerging. During our evaluation of the above mentioned solutions we had opportunity to produce and, according to the solution used, compare three quantitatively comparable groups. These issues are the subject of a number of research projects which have appeared in technical literature and with which we can compare our results ${ }^{11}$.

These showed, that when we evaluated immediate graft function, HTK and UW solutions were more suitable than EC solution. In our set up, HTK had primary function in $73.7 \%$ of cases and delayed function in $23.6 \%$. UW, primary in $71.5 \%$, delayed in $26.2 \%$. EC had primary function only in $51.1 \%$ and delayed function in $46.8 \%$. Primary afunctionl grafts showed in all three groups equally frequently: HTK $2.7 \%$, UW $2.3 \%$, EC $2.1 \%$. These equal values indicate, that afunction is not dependent on solution.

The serum creatinine value was a parameter of shortterm as well as long term graft function. The immediate results showed, that a significant decrease in serum creatinine was recorded three weeks after transplantation in kidney preserved by HTK and UW solutions (average serum creatinine value in the HTK group $279 \mu \mathrm{mol} / 1$, in UW $288 \mu \mathrm{mol} / \mathrm{l})$. In the EC group, the decrease in serum creatinine was significantly smaller, the average value was $429 \mu \mathrm{mol} / \mathrm{l}$. Statistical processing indicate, that there was no significant difference $(\mathrm{p}=0.881)$ between the HTK and UW solutions, more accurately, between serum creatinine in grafts preserved by these solutions. On the other hand, there was a statistically significant difference between EC and HTK solutions, $p=0.016$, the same as between EC and UW, where there was a significant difference $\mathrm{p}=0.020$.

In the first year after transplantation, the creatinine levels in all three groups leveled out, HTK $154 \mu \mathrm{mol} / 1$, UW $128 \mu \mathrm{mol} / 1$ and EC $154 \mu \mathrm{mol} / 1$. A statistically significant difference was not shown. EC and HTK: $p=0.851$, EC and UW: $\mathrm{p}=0.058$, HTK and UW: $\mathrm{p}=0.096$.
In the third year of monitoring, the following average serum creatinine results were shown: EC $173 \mu \mathrm{mol} / 1$, HTK $181 \mu \mathrm{mol} / 1$, UW $128 \mu \mathrm{mol} / 1$. There was no significant difference between EC and HTK, $p=0.895$. There were statistically insignificant differences between $\mathrm{EC}$ and UW and between HTK and UW: $p=0.033$ and $p=0.037$.

In the fifth year, the following average serum creatinine values were found: EC $154 \mu \mathrm{mol} / 1$, HTK $182 \mu \mathrm{mol} / 1$ and UW $133 \mu \mathrm{mol} / 1$. There was a statistically insignificant difference between EC and HTK groups, $p=0.076$ and between EC and UW groups, $p=0.323$. HTK and UW groups comparison shows a minimal significant difference, $\mathrm{p}=0.009$.

Our results from monitoring immediate results are similar to those of Hoyer's, who evaluated development of serum creatinine levels at various time periods after transplant - in the first week, when the results are clearly best with HTK, in the $2^{\text {nd }}$ and $3^{\text {rd }}$ week the values are comparable for HTK and UW as opposed to EC, but in the third week after transplant, the creatinine values were the same in all three groups.

As far as number of functional grafts comparison is concerned, results in living patients were as follows: in the first year: EC - $100 \%$, HTK - $100 \%$ and UW - $92.3 \%$.

In the second year, there was $94.1 \%$ of functional grafts in EC, HTK - $100 \%$, and UW - $84.6 \%$.

In the third year: EC and HTK - functional grafts in $100 \%$ cases, UW - $84.6 \%$.

In the fourth year: EC $-92.8 \%$, HTK - $100 \%$, UW $-76.9 \%$.

In the fifth year: EC and HTK - $100 \%$, UW $-76.9 \%$.

We processed all these values statistically using $\log$ Rank analysis, which compares Kaplan - Meier curves. The results showed, that as far as survival of functional grafts is concerned, there were no statistically significant differences in EC, HTK and UW groups monitored for five year period. In transplantation where EC, HTK and UW solutions were used and were performed after 1995, $\log$ rank test $=0.66$.

\section{CONCLUSION}

We may conclude, that in comparing our immediate results with similar projects from abroad, some of our anticipated results are comparable with the literature. Five year monitoring of transplanted kidney function relative to a protective solution used is quite unique, however.

From the standpoint of immediate transplanted kidney function, the results are significantly better with kidneys treated by HTK and UW solutions. Good and early kidney function has a very positive effect on patients who do not need supporting dialysis in the post-transplant period and hospital stay is shortened. The positive psychological effect should not be underestimated as well. There is also an economic aspect to consider as the transplantation cost is lower than the cost of dialysis therapy. 
It is surprising, that in the long-term function of transplanted kidney, there is no difference between individual solutions in the first year after the transplant. Also in the third and fifth year after transplant, the differences between individual solutions are minimal. This finding is in conflict with general experience, that there is usually a rather negative long-term function prognosis for transplanted kidney with a complicated start-up of its function. While an early function of kidney treated by HTK or UW solution, as opposed to EC, is an obvious benefit, in the long-term functioning this is not a major factor.

EC solution is, for this reason considered to be obsolete. In isolated cases, EC is used at some institutions abroad for kidney "single" removal.

UW solution, in spite of the fact, that in the literature, it is often called "golden standard", is presently rarely used in the Czech Republic, because its high viscosity complicates application.

HTK has very good immediate as well as long-term results in the preservation of kidney and other organs. Due to efforts to perform the largest multi-organ removals possible, when the organs are rinsed at the same time, it is used in most of the transplantation centers.

\section{REFERENCES}

1. Transplantation Law no. 285/2002, Ministry of Health regulation no 437/2002, Ministry of Health regulation no. 479/2002.

2 Hesse UJ, de Hemptinne B. (1999) Organ preservation with HTK and UW solution. Pabst Science Publishers.

3. Hölscher M, Groenewould AF. (1991) Current Status of the HTK solution of Bretschneider in organ Preservation. Transplantation Proceedings 23, 2334-2337.

4. Chandraker A. (1999) Ischemia-Reperfusion Injury in Experimental Models of Organ Transplantation. Transplantation Proceedings 31, 2073.

5. Collins GM, Bravo-Shugarman M, Terasaki PI. (1969) Kidney preservation for transplantation. 3. Initial perfusion and 30 hour storage. Lancet ii 1219-1222.

6. Mühlbacher F, Langer F, Mittermayer C. (1991) Preservation Solutions for Transplantation. Transplantation Proceedings 31, 2069-2070.

7. Bretschneider HJ, Helmchen U, Kehrer G. (1998) Niereprotektion. Klinische Wochenschrift 66, 817-827.

8. Hatano E, Tanaka A, Shinohara H, Kitai T, Satoh S, Inomoto T, Tanak K, Yamaoka Y. (1996) Superiority of HTK solution to UW solution for tissue oxygenation in living related liver transplantation. Transplant Proc 28, 1880-1881.

9. Belzer FO, D‘Allessandro AM, Hoffmann RM, Knechtle SJ, Reed A, Pirsch JD, Kalayoglu M, Sollinger HW. (1992) The use of UW solution in clinical transplantation. A 4-year experience. Ann Surg 215, 579-583; discussion 584-585.

10. Belzer FO, Kalayoglu M, D'Alessandro AM, Pirsch JD, Sollinger HW, Hoffmann R, Boudjema K, Southard JH. (1990) Organ preservation: experience with University of Wisconsin solution and plans for the future. Clin Transplant 4, 73-77.

11. Roels L, Peeters J, Vanrenterghem Y. (1996) Delayed Graft Function as Principal Correlate of Kidney Allograft Outcome in a Single-Center Multivariate Analysis. Transplant Proc 28, 1582. 